http://dx.doi.org/10.12795/RAA.2014.i07.05

\title{
LA NOCIÓN DE ETNICIDAD Y LA SITUACIÓN DE LOS ROM: UN CUESTIONAMIENTO RUMANO ${ }^{*}$
}

\section{Martín Olivera}

\author{
Laboratoire d'Anthropologie Urbaine, IIAC-Lau (CNRS-Ehess)
}

\begin{abstract}
Resumen
¿Por qué preguntarse si los Rom, especialmente en Rumanía -ya que ésta es la situación que se abordará aquí- constituyen efectivamente una "minoría étnica"? En lugar de aportar una respuesta concluyente y definitiva a esta pregunta, el objetivo de este artículo consiste en primer lugar en cuestionar las categorizaciones habituales y evaluar su incapacidad para entender aquello que define la originalidad y la singularidad de las sociedades rom rumanas, en su diversidad.
\end{abstract}

Palabras clave.

Rom, Rumanía, etnia, identidad

\begin{abstract}
Why wonder if the Rom, especially in Romania -and this is the situation addressed here- effectively constitute an "ethnic minority"? Instead of providing a conclusive and definitive answer to this question, the aim of this paper is first to question the usual categorizations and evaluate their inability to understand what defines the originality and uniqueness of the Romanian Rom societies, in their diversity .
\end{abstract}

$1^{\star}$. Este artículo fue publicado por el autor con el título "Les Roms comme "minorité ethnique"? Un questionnement roumain". En EtudesTsiganes 39-40:128-140, 2011. El texto que se presenta a continuación es una versión ligeramente modificada del mismo. Traducción del original realizada por David Lagunas, con autorización del autor. 


\section{Keywords.}

Rom, Romania, ethnic, identity

Los Rom constituyen en Rumanía una de las veinte "minorías nacionales” reconocidas por el Estado. La categoría “etnia” (etnie) se moviliza de manera explícita en los documentos oficiales, sobre todo en los censos nacionales, junto con otras características (sexo, edad, etc.). Oficialmente, la población Rom es de poco más de 600.000 (censo de 2012), o más de dos millones según algunas estimaciones al alza (ONG). Aunque principalmente son percibidos como población desfavorecida, los Rom son por otro lado el objeto de políticas específicas implementadas por una agencia del gobierno dedicada a ello: A.N.R. (Agencia Nacional para los Rom).

Aparte de las cuestiones socio-económicas, este reconocimiento oficial de la condición de "minoría" pretende poner en valor la historia y la cultura de las comunidades rom para romper con la imagen de los grupos marginales, estructurados por la anomia. En una palabra, se trata de positivar la "identidad rom", con demasiada frecuencia definida por defecto (de integración, cultura, moral, salud, etc.). Esta pretensión no puede, sobre el papel, orientarse a otra cosa que a la promoción. Entonces, ¿por qué preguntarse si los Rom, especialmente en Rumanía -ya que ésta es la situación que se abordará aquíconstituyen efectivamente una "minoría étnica"?

En lugar de aportar una respuesta concluyente y definitiva a esta pregunta -para la cual, dicho sea de paso, la ciencia no tiene ninguna legitimidad para responder, por las razones que veremos-, el objetivo de este artículo consiste, en primer lugar, en cuestionar las categorizaciones habituales y evaluar su incapacidad para entender aquello que define la originalidad y la singularidad de las sociedades rom rumanas, en su diversidad. Aquí como en otras partes, se da el caso de que iniciativas loables no hacen sino desplazar la ignorancia, sin poner en cuestión sus resortes, especialmente bien engrasados en el caso de los gitanos ${ }^{2}$.

Por otro lado, y más allá de la ambición estrictamente científica para una mejor comprensión de las realidades socio-culturales, el contexto actual no es inerme respecto a las razones que motivan tal pregunta: definir y/o "reconocer" la existencia de un grupo

2. A partir de su trabajo entre los Rom en la Hungría socialista en los años 80, Michael Stewart viene a formular una constatación similar: "In Europe it has become one of those taken-for-granted "facts" that everyone nowadays has an "ethnic" identity in the sense of more or less primordial, unchosen, traditional identity into which he or she was born. [...] My extended experience in Hungary and shorter trips elsewhere in eastern Europe have convinced me that, with the exception of the educated Gypsy intellectuals who run the Rom political parties, the Rom do not have an ethnic identity" (Stewart, 1997:28). 
humano particular con el fin de llevar a cabo una política específica hacia el mismo no es un asunto trivial. Es, sin embargo, y en relación con los gitanos, la tarea que se está realizando desde hace varios años a diferentes niveles: local, nacional y continental. Ciertamente, la "política gitana" existe en el seno de los estados europeos, por acción u omisión, al menos desde el siglo XIX, incluso con efectos negativos y dramáticos bien conocidos (cf. por ejemplo, Huonkery Ludi, 2009). La novedad actual reside en la corriente internacional, coordinada y explícitamente institucionalizada de esta política, asumiendo que los Gitanos (Rom, Gitanos, Sinti y otros Viajeros) constituyen globalmente un "pueblo", una "etnia" o una "minoría". No se trata solamente de preocupaciones nacionalistas, sociales y/o policiales, las cuales, como en otras ocasiones, fundan las políticas dirigidas hacia estos grupos, sino también, oficialmente al menos, de un saber positivo: las instituciones se apoyan, más o menos directamente, sobre diversos conocimientos históricos, lingüísticos, sociológicos y antropológicos desarrollados a lo largo de las últimas décadas, para definir a los Gitanos sui generis como entidad sociocultural objetiva.

La ciencia es, así, interpelada a participar en la escena pública, en virtud de una garantía racional motivando o, más bien, justificando las políticas implementadas. Sus practicantes atesoran entonces toda la legitimidad para generar y preservar el debate y los cuestionamientos sobre el tema, argumentando de manera particular que los conocimientos que ellos producen son, por naturaleza, matizados, diversos, contradictorios y nunca pueden revelarse como evidencia única (Bachelard), mucho menos en el campo de las ciencias humanas.

Desde este punto de vista, la antropología tiene cosas que decir acerca de la forma incorrecta en que son generalmente abordados los grupos gitanos. Lo ha hecho durante muchos años, pero de manera a menudo discreta. Leonardo Piasere resumía así la situación en 1988:

"Me parece que, en los últimos años, estamos asistiendo a la formación de un frente anti-etnólogos heterogéneo, formado tanto por líderes gitanos y no-gitanos que habitan en los alrededores y en los contornos del mundo gitano. [...] Después de escuchar una de mis comunicaciones sobre "Los Gitanos en Italia", Rajko Djuric (secretario de la Unión Romaní) me reprochaba el hecho de destruir a los Gitanos al reducirlos a una miríada de grupos y poner el acento excesivamente en sus peculiaridades. [...] Con su carácter agradable y amigable [él] me acusaba suavemente de ser un "tribalista arcaico" [...] En resumen, me parece que estamos en la peor situación entre todos los gitanólogos. Historiadores, sociólogos, lingüistas y educadores no conocen ciertamente las críticas que llueven sobre los etnólogos [...] Mientras trabajan en la redacción de una historia olvidada o construir un futuro glorioso, estos otros son unos eruditos de gran mérito; y 
nosotros, delatores retrógrados [...] ¿La gitanología del año 2000 habrá de caer bajo el yugo de los dirigentes políticos y/o religiosos gitanos?" (Piasere, 1989:104$105)$.

Más de veinte años después de esta pregunta la situación es muy similar, a excepción de que, con la caída del Muro de Berlín, se ha acelerado la propagación del discurso militante pan-gitano y su institucionalización: el "reconocimiento" y la "integración" de los Rom, definidos como minoría marginada, se ha convertido en símbolo de la nueva Europa, "democrática y reunificada". Finalmente se deja poco espacio, por lo menos en el ámbito público, a las perspectivas que ponen de relieve la diversidad histórica, social y cultural de las sociedades gitanas, siendo tales posiciones un compromiso sensato para la movilización respecto de una "causa" ampliamente aceptada. Se olvida que los investigadores están tratando de dar cuenta de la realidad que observan en su complejidad, sin la injerencia de un tema político global y, en todos los casos, sin ningún tipo de juicio moral. Por supuesto, el positivismo ingenuo ha desaparecido desde hace mucho tiempo y los científicos saben que no son pensadores inmaculados, definitivamente alejados de los problemas de este mundo. Ello no impide que el conocimiento que producen sea de una naturaleza particular, debido a que es parte de un campo estructurado, delimitando y discutiendo constantemente el alcance de su validez $z^{4}$.

En este contexto y con estas condiciones, el científico goza de una libertad fundamental, como nos recuerda a su estilo Raymond Aron (1959:25-27):

"Que las ciencias sociales no parten nunca de una tabula rasa, que la posición de los problemas sea suscitada por los acontecimientos, que el método no sea independiente del contexto histórico, que a menudo los resultados sean influenciados por los intereses de las naciones y clases, nosotros no pensamos

3. Cf. la presentación de las acciones de la Division Roms et Gens du Voyage en el Consejo de Europa, creada en 1994: "El objetivo principal de la Organización es el de promover un acercamiento global sobre las cuestiones rom de los Estados miembros. Para este efecto, se han establecido tres prioridades esenciales: la protección de las minorías, la lucha contra el racismo, el antigitanismo y la intolerancia, y el combate contra la exclusión social". Para un análisis atinado de los fundamentos teóricos e ideológicos fabricados en la europeización de la "cuestión rom" según el modelo de la "sociedad abierta" puesto al día. Ver Asséo (2005).

4. He aquí tal vez las carencias que han afectado durante mucho tiempo a los denominados "estudios gitanos", al menos en lo que respecta al campo antropológico hasta los años 80 , como señala Piasere (1994:21): "La etnografía gitana acumula así retrasos de varias décadas en comparación con el pensamiento antropológico (en los años 60, más de un autor encuentra todavía, un poco por todos lados en Europa, Gitanos matriarcales...). Ello se asentó en el seno de una "gitanología" que se presentaba, y se presenta todavía en parte, no tanto como un conjunto de estudios interdisciplinarios sino como un "cajón de sastre" gitano". 
negarlo. No sería un despropósito menor llegar a la conclusión de que las ciencias sociales son sólo ideologías de clase o de raza y que la ortodoxia impuesta por un Estado totalitario no difiere en su naturaleza de la investigación libre en las sociedades pluralistas. Existe, se diga lo que se diga, una comunidad de ciencias sociales, menos autónoma que la comunidad de ciencias naturales, pero no menos real. ¿Cuáles son las reglas constitutivas de esta comunidad de ciencias sociales?

$1^{\circ}$ En primer lugar, la ausencia de restricción en la investigación y la fijación de los hechos en sí mismos [...];

$2^{\circ}$ En segundo lugar, la ausencia de restricción al derecho de discusión y crítica, aplicado no sólo a los resultados parciales, sino a los fundamentos y los métodos $[\ldots]$

$3^{\circ}$ Por último, la ausencia de restricción al derecho a desencantar lo real [...]

Es inusual que un científico utilice estas tres libertades, simultáneamente y sin limitaciones, sería casi inhumano que lo hiciera. La comunidad de ciencias sociales tiene precisamente por función crear, a través del diálogo y la crítica mutua, el equivalente de estas tres libertades".

En el actual clima de crispaciones nacionales respecto a la seguridad, en el cual los Gitanos son identificados como migrantes indeseables por excelencia (cf. por ejemplo, los acontecimientos recurrentes en Italia en los últimos años o las políticas francesas combinando "campamentos" y rechazo de los inmigrantes Rom), es urgente comunicar los puntos de vista y los análisis matizados producidos por los investigadores, para deconstruir mejor los esquemas unívocos que transforman a estas poblaciones en un "problema público" a resolver.

A partir de mi trabajo entre los Gabori de Transilvania (Olivera, 2012), el curso de este artículo se desplegará en torno a tres cuestiones sucesivas:

- ¿Los Rom de Rumania se ajustan a la definición primordialista de la etnia?

- ¿Los Rom de Rumania se conforman al enfoque circunstancialista de la etnicidad?

- ¿Qué se puede deducir para el estudio de las realidades Rom?

\section{1. ¿LOS ROM DE RUMANIA SE AJUSTAN A LA DEFINICIÓN PRIMORDIALISTA DE LA "ETNIA"?}

¿Qué se entiende habitualmente por "etnia"? Según el Robert historique de la langue française, se trata de "un conjunto de individuos que comparten una serie de características de civilización, particularmente el idioma". La raíz indoeuropea de ethnos sería swe-swedh, designando "aquello que existe de manera autónoma, que tiene su propia existencia" (esta raíz dio lugar a "se" y "soi" en francés). 
Esta definición corresponde a la opinión común que percibe la etnia como un grupo humano "natural", caracterizado por "rasgos culturales", un "patrimonio" propio, incluido el idioma. En esta lógica sustantivista, la etnia es a los antiguos colonizados lo que la nación es a los antiguos colonizadores: los "étnicos" se complacen con mitos fundadores mientras que los "nacionales" hacen Historia.

Para A. C. Taylor (1991:242) "la nueva terminología que se elabora [en el siglo XIX colonial, en que el término "etnia" es un elemento central] permite ubicar en su lugar a las poblaciones conquistadas, dividirlas y confinarlas por medio de definiciones territoriales y culturales unívocas". Citando particularmente el ahora célebre libro de J. L. Amselley E. M’Bokolo (1985), concluye que "se revela que la cristalización de las etnias remite invariablemente a procesos de dominación política, económica o ideológica de un grupo sobre otro". El enfoque sustantivista o primordialista ha sido de esta forma ampliamente cuestionado en antropología en los últimos treinta años. Pero los investigadores se hallan casi en solitario al dar por sentada esta deconstrucción.

De manera ejemplar, la definición adoptada por el proyecto de ley de "minorías nacionales", discutido en Rumanía desde hace varios años, se ajusta perfectamente a la percepción esencialista de las sociedades humanas:

Artículo 3, párrafo 1: "Por 'minoría nacional', se entiende cualquier comunidad de ciudadanos rumanos, viviendo en el territorio de Rumanía desde al menos cien años, poseyendo supropiaidentidad nacional, étnica, culturaly religiosa, la cual es numéricamente inferior a la población mayoritaria y quiere preservar, expresar y promover su identidad" Si aceptamos provisionalmente esta concepción de las identidades colectivas, ¿cuál podría ser, en el caso de los Rom de Rumania, esta "identidad nacional, étnica, cultural y religiosa" que los conformaría en tanto que un grupo distinto?

Existe, no obstante, un discurso "nacional" rom elaborado en el seno de movimientos militantes, basado en el saber gitanológico: fundado en la idea de un origen indio común, el nacionalismo rom se ha dotado de una lengua estandarizada, una bandera, un Día Internacional del Pueblo Gitano (8 de abril) y un himno (el famoso Gelem Gelem popularizado por Goran Bregovic) -cf. "Statut cadre du peuple rrom», op. cit. Hasta la fecha, la empresa militante se halla bastante alejada de las realidades cotidianas y goza de mayor resonancia entre las diversas instituciones en lugar de las comunidades locales rom.

Recordemos en primer lugar que lospropios interesados no refieren a un territorio de origen distinto a su lugar de residencia: el "origen indio" no tiene sentido entre los Gabori. Y cuando, en ocasiones, algunos se apropian de esta hipótesis escuchada en la televisión o leída en el periódico, es para desviarla mejor, a su manera: "Nosotros, sí, tal vez venimos de la India [sobre-entendido: “isi tú lo dices!”], pero ellos [esos otros Gitanos, de otro 
lugar] vienen de África, es por eso que son salvajes, malos", he escuchado repetidamente como una lógica muy diferente del origen común y homogeneizador ${ }^{5}$.

De manera harto evidente, los territorios que forman la actual Rumania testimonian una historia diversa, habiendo sido objeto de diversas influencias (eslava, bizantina, otomana, rusa, austro-húngara, etc.). Y las comunidades rom no han sido impermeables a este pasado que es también el suyo, en toda su complejidad (cf. Olivera, 2010). La experiencia de la Segunda Guerra Mundial, por ejemplo, no fue análoga para el conjunto de las comunidades: en Transilvania algunos hombres combatieron a los rusos en las tropas húngaras en el frente oriental, cuando, por otra parte, otros grupos familiares fueron deportados por el Gobierno rumano en Transnistrieen tanto que "Gitanos nómadas".

Desde un punto de vista cultural, los frutos de la diversidad histórica se expresan todavía hoy. Se encuentran Rom de diversas confesiones: ortodoxos, católicos, uniatos, protestantes, neo-protestantes, y entre estos últimos, varios cultos (pentecostales, adventistas, bautistas, testigos de Jehová...). Las diferentes comunidades practican diversas tradiciones vestimentarias, matrimoniales, profesionales, etc., pero también diversos idiomas: ciertos grupos no hablan el romanés sino únicamente el rumano y/o el húngaro según las regiones rumanas y/o húngaras, mientras que los hablantes del romanés dejan entrever una gran variedad dialectal, no siempre posibilitando una comprensión mutua -y además es necesario, para tratar de reencontrarse y comunicarse, lo cual no es fácil.

Por supuesto, algunos grupos se asemejan más entre ellos debido a la proximidad histórica y geográfica: se observan así muchas similitudes entre Rom Gabori de Mureş y Rom Ciurari del Valle de Târnava. Sin embargo, estas comunidades también se parecen a sus vecinos, rumanos o húngaros, y a menudo más a estos últimos que a otros "hermanos étnicos" rom que viven en regiones remotas (por no hablar de los Gitanos de otros países).

$\mathrm{Si}$, de todos modos, se pretende identificar a toda costa "grupos culturales" rom, portadores de una "identidad específica", es imprescindible atenerse a una cartografía de las comunidades locales: los rom de una región en particular, incluso de un conjunto de pueblos, compartiendo unas costumbres vestimentarias, un hablar romanés, una historia local, etc.

Desde este punto de vista, los rom Gabori parecen representar el grupo ideal:

- son todos originarios de un territorio determinado: una red de pueblos en el departamento de Mureş;

5. Cabe hacer notar que, en esta misma lógica, la Wikipedia en lengua rumana dedica una sección a los "Yéniches" en la que los Gabori son identificados como "Yéniches rumanos", para distinguirlos de otros Tigani "de origen indio" ... Si tal interpretación no tiene ninguna base rigurosa, no es menos indicativa de la forma en que puede instrumentalizarse la cuestión de los "orígenes". 
- hablan romanés de forma parecida, reflejando importantes influencias húngaras;

- poseen una estética tradicional que le es propia: bigotes largos, amplios sombreros de fieltro negro y ropa oscura para los hombres / faldas largas y ligeras plisadas, pañuelos combinados de una manera particular, etc. para las mujeres;

- detentan un "oficio tradicional": el cubrimiento-zinguerie (en particular la colocación de bajantes)

- son casi todos católicos y evangélicos (pentecostales, adventistas, baptistas o testigos de Jehová);

- practican el matrimonio por dote y poseen linajes "nobles" (rajkaneviţi) al interior de los cuales se transmiten cálices de plata (taxtaj);

En resumen, estos Rom hacen gala actualmente de todos los atributos usuales de una etnia: un etnónimo, un territorio de origen, un idioma y tradiciones percibidas como específicas (vestimentarias, profesionales, matrimoniales, etc.). Se conforman así, en su discurso dirigido al menos a los Otros, a la ideología primordialista y su concepción de las sociedades humanas.

Hagamos notar sin embargo que este hecho no es común al conjunto de los grupos Rom de Rumanía: son numerosos aquellos que no reivindican ningún etnónimo particular y no se caracterizan por una ostensible "identidad comunitaria". Sus ocupaciones profesionales al igual que su vestuario, por mencionar dos atributos muy visibles y frecuentemente movilizados en la identificación de los "grupos rom tradicionales", no los singularizan en realidad respecto de otros grupos que les rodean. Estos grupos locales, no obstante más discretos, no forman a pesar de todo grupos sociales particulares y ampliamente endógamos, cuyos miembros se distingan de manera evidente a primera vista respecto a "otros Gitanos" al igual que los Gajé.

Una perspectiva esencialista escrupulosa nos revelaría de este modo docenas y docenas de "etnias rom" diferentes, así como numerosas "minorías nacionales" potenciales, contando cada una de ellas con varios miles de individuos -como máximo-. Eso complicaría considerablemente la organización institucional del país si se requiriera representarlas a todas...

Pero eso no es todo. Si así resultara inevitable, el ejemplo de los Gabori muestra por qué el enfoque primordialista no sólo es insostenible para el gobierno (!), sino también es erróneo desde el punto de vista de la comprensión sociológica. Entre los Gabori como en cualquier otra sociedad humana, la perspectiva histórica, aunque modesta, demuestra que los "rasgos culturales" nunca son como piedras inmóviles, incluso los erigidos en símbolos nacionales (cf. Hobsbawm y Ranger, 1992).

Las investigaciones muestran de hecho cómo estos "Romauténticos y tradicionales" han 
literalmente reinventado sus tradiciones, al menos la parte visible (vestuario, actividad profesional y, de manera significativa, el etnónimo), en el transcurso de los últimos cuarenta años:

- el oficio "tradicional" de zingueurse ha generalizado entre las familias a partir de los años 60: los mayores adquieren sus habilidades de antiguos patrones o amigos gajé, no de sus propios antepasados ...;

- el sombrero de ala ancha y fieltro negro, estandarte contemporáneo de los Gabori "Rom con sombrero", no apareció hasta los años 80-90 -el ensanchamiento de sus rebordes no se ha completado por lo general hasta la fecha...;

- el etnónimo mismo Gabor parece haberse extendido entre estos Rom en los últimos treinta años: de manera harto reveladora, el etnónimo nunca se emplea entre ellos sino sólo en relación con los gajé como etiqueta generalmente bien aceptada, la de los Gitanos tradicionales “respetables” (ver Houliat, 1999:128).

Aunque el análisis de los procesos de reinvención de la tradición llevados a cabo por los Gabori a lo largo de más de dos generaciones está fuera del alcance de este artículo, podemos constatar que este grupo ha adoptado públicamente, a diferencia de otros Gitanos rumanos, una "identidad étnica” propia o, al menos, presentada como tal. Porque, en efecto, un estudio detallado de los "rasgos culturales" Gabori demuestra la profunda integración de estos Rom en el contexto cultural local, en lugar de la perpetuación de una identidad exótica (heredada de la India o de otro lugar): la organización del parentesco, como de las prácticas vestimentarias, por ejemplo, remite directamente a las realidades del espacio rumano y transilvano (cf. Olivera, 2012, capítulos 3 y 4).

Después de haber registrado y disecado por largo tiempo a los grupos étnicos, la antropología insiste desde hace más de treinta años en la idea de que las identidades colectivas no son objetos sino construcciones; la humanidad no está conformada por "naciones", "pueblos" o "etnias", definidas como entidades discretas, sino por sociedades en contacto las unas con las otras, las cuales manipulan las identidades colectivas, pudiendo cada individuo adscribirse, en contextos diferenciados, a diferentes grupos sociales. Determinadas sociedades movilizan una retórica esencialista, como en nuestros Estados-nación llamados "modernos" y, de forma marginal en los últimos años, los Gabori, mientras otras no hacen nada al respecto.

En términos más generales, el análisis de las realidades socioculturales Gabori respalda la idea según la cual toda sociedad es por naturaleza mestiza, en el sentido de Amselle (1990).Sostener que los Rom de Rumanía no se ajustan a la lógica "étnica" no significa reconsiderarlos grupos humanos de forma predeterminada, definidos de manera negativa. Ello constituye, por el contrario, el pre-requisito necesario si queremos comprender la 
rica diversidad de estas sociedades y la manera original de estar en el mundo, la cual se aparta muy claramente de un discurso reificador de la identidad colectiva.

Pero si los Rom, al igual que cualquier otro grupo humano, no pueden ser caracterizados por un patrimonio histórico-cultural primordial y definitivamente propio, ¿tal vez posean en común una etnicidad, o una manera de afirmarse colectivamente, materializado en "fronteras étnicas" comunes?

\section{LOS ROM DE RUMANIA, ¿UN «GRUPO ETNICO»SEGUN BARTH?}

Como es bien sabido, una ruptura importante fue operada en la antropología en el estudio de la identidad étnica con los trabajos de F. Barth (1969) y sus continuadores: en lugar de abordar la etnia como un grupo social de facto definido por un contenido, Barth aboga por el estudio de la etnicidad, entendida como "las diferentes modalidades por medio de las cuales las diferencias culturales resultan pertinentes para la organización social" (Poutignat y Streiff-Fenart, 1995). De ahí el cambio de enfoque de la mirada sobre las fronteras étnicas en tanto que lugar estratégico de la afirmación colectiva: ésta tiene lugar en la interacción con el Otro.

Este tipo de conceptualizaciones remiten en parte a las ideas de Max Weber según el cual el "grupo étnico" se define fundamentalmente por una conciencia de pertenencia (Weber, 1971:124-143), desde un punto de vista más general, y a Leach (en Bonte e Izard, 1991:668) quien señala que una sociedad se caracteriza por el uso de un "nosotros". Esta es una perspectiva que puede parecer más pertinente para captar el conjunto de los Rom rumanos desde un mismo ángulo: a pesar de parecerse "objetivamente", tendrían en común, precisamente, el hecho de auto-designarse como Rom. Pero, de nuevo, las cosas no son tan simples.

En primer lugar, tal enfoque excluye de facto los grupos cuyos miembros no son hablantes de romanés 6 . Desde el momento en que se expresan en rumano o húngaro, los interesados emplean de hecho casi siempre los términos țigan o cygan, raramente el término políticamente correcto rrom: este está reservado a las instituciones y discursos mediáticos. En consecuencia, aquellos no hablantes de romanés en general no se reconocen nunca como "Rom".

Además, los miembros de las comunidades donde el romanés es la lengua maternal (junto con el gajikanés, rumano o húngaro según el lugar) no entienden lo mismo en la locución "Nosotros, los Rom" (Ame, ol Roma). Para volver al ejemplo gabor, cuando dicen: "Nosotros, los Rom", con ello quieren significar: "Nosotros, los que nos llamamos

6 Según el censo de 2002, de los 535000 Romi censados, 43\% declararon el romanès como lengua materna. 
Gabori"'.De manera evidente respecto a su punto de vista, este "Nosotros" se refiere a un simple espacio de semejanzas, no a una vasta categoría integrada por subcategorías. De ahí la inutilidad del etnónimo Gabor en sus interacciones: no tiene relevancia. Y si fuera realmente necesario precisar a un espíritu confuso -el etnógrafo novato por ejemplo- a qué "Rom" se refieren, los interesados aclaran, desconcertados e incapaces de callarse simultáneamente al definir el "Nosotros” mejor que la tautología: “¡Eh, nosotros! ¡los Romrom!(¡Ame, romané Roma!)”. No existe en su percepción un meta-grupo del cual ellos serían únicamente un elemento. En otros términos, los Gabori no se representan como "minoría entre la minoría", sino que se afirman como natia (nación) propia y suficiente. Los semejantes a ellos son aquellos con los que las uniones matrimoniales son naturalmente posibles, porque, precisamente, son ya parientes más o menos lejanos ${ }^{8}$.

Por otro lado, estos Romman tienen diversas "fronteras étnicas", lo cual nos lleva a descartar una simple oposición face to face Rom/Gajé. En efecto, se encuentran por doquier las figuras de la alteridad:

- Los más numerosos: los Gajé. Sin embargo el uso del término es variable, dependiendo de los contextos. Puede significar el vecindario cercano, o la totalidad de los habitantes de Rumania definidos como no-Gitanos, o incluso todos aquellos (personajes de telenovelas incluidos) que se amoldan a los estereotipos del Occidental "moderno". Por otra parte, existe dentro de la vasta categoría Gajé un tropel de distintas sub-categorías distintas, consideradas más o menos similares: los Transilvanos (Ardeleni), Moldavos, de Bucarest, Olténiens etc.;

- Los Otros muy otros: los Africanuri (Africanos) y Chinezuri (Asiáticos), figuras radicales de la alteridad, no son equivalentes a los Gajé. No es tanto el color de la piel lo que determina la categorización (aparecen Gajé afroamericanos y asiáticos en las series de televisión), como el estilo de vida percibido -o fantasmal;

- Los Otros peores: los Řumunguri definidos como "Gitanos malogrados", sin lengua (solo hablan gajikanés, el húngaro, de ahí el concepto), sin cultura, sin moral, etc. Los Řumunguri juegan entre los gabori el rol del doble negativo, anti-social por excelencia, amenazando el saber-vivir romanés y sus virtudes;

- Los Otros locales pero exóticos: los ţerhari (cortorari en rumano), o Gitanos nómadas que viven en tiendas de campaña. Estos son tigani percibidos como "atrasados", con los cuales pueden mantenerse relaciones comerciales o de amistad, sin desembocar en alianzas matrimoniales: jestos Gitanos son demasiado extraños!;

7. La expresión equivalente en rumano sería "ainoştrii": "los nuestros".

8. Existen obviamente matrimonios exogámicos, los cuales no hacen sino confirmar la regla, cf. Olivera (2012, capítulo 4). 
- Los Otros muy cercanos: los Ciurariy Giurgiuvoie, Gitanos originarios de regiones próximas respecto a los cuales la etiqueta Roma es más fácilmente atribuida, aunque los Gabori prefieren utilizar estos etnónimos específicos para distinguirlos de los verdaderamente semejantes a ellos -incluso si en ciertas familias las fronteras parecen más borrosas, a raíz de los matrimonios;

- Los Otros idénticos: en el seno de la nación gabor, se hallan grupos de parentesco distintivos, los viţi, pseudo-linajes en línea agnática preferentemente endógamos. Permitiendo la perpetuación de las lógicas del prestigio y nobleza familiar, los viţiy su manipulación promueve según el punto de vista de los Gabori la naturaleza particular de su nación y su endogamia.

Este podría ser un ensayo (rápido) de definición de la etnicidad gabor. Las fronteras étnicas, muy variables y fuertemente instrumentalizadas, son por definición las propias de los Gabori puesto que ellos se incluyen en tanto que tales en este juego de espejos. ¿Es además necesario precisar que aquellos clasificados como Řumunguri oţerhari no forman entidades socioculturales reales? Una tipología como ésta de la alteridad es, pues, válida sólo para los Gabori.

Buscando, al menos, un mínimo punto en común, ¿tal vez podríamos considerar que todos los Rom movilizan una categoría idéntica, la de los Gajé? Una vez más, esto significaría excluir inicialmente a todos aquellos no hablantes de romanés quienes, por definición, no utilizan el término: si se encuentran imágenes aproximadas en rumano y húngaro para dar cuenta de lo que designa la palabra, ello aplicaría sin que existiera una traducción real.

Indudablemente, el ejemplo gabor muestra que la categoría "Gajé" es relativa y cambiante: según las comunidades y los contextos, no remite en concreto a las mismas realidades socio-culturales ${ }^{9}$. Ciertamente, los Gajé poseen un aspecto en común: independientemente de las variaciones nacionales y regionales, son ellos los primeros que se afirman como "nacionales", allí donde los Gitanos se contentan al estar incluidos como tales. Pero, como he podido demostrar por otro lado (cf. Olivera, 2012:1-15), es más bien la intimidad con sus Gajé lo que estimula la identidad original de una sociedad rom en lugar de un simple esquema de oposición binaria.

En suma, los Gajé no son todos idénticos y, de hecho, los diversos grupos Rom no mantienen una misma relación con sus Gajé. En consecuencia, la recurrencia de la distinción Rom/Gajé no genera tanto una homogeneización de la "identidad Rom" como la diversificación perpetua de las comunidades locales. En lo que concierne a

9. En este sentido, he podido constatar que los Rom rumanos (no Gabori) instalados en Francia en los últimos años utilizan más frecuentemente Francezi que Gajé para designar a aquellos que los rodean, siendo el Gajo desde su punto de vista -por el momento - identificado con el Rumano. 
los Gabori, el "orgullo nacional" no se construye distinguiéndose incesantemente de la categoría de los Gajé, sino más bien en oposición a los Řumunguri y, aunque de manera menos pronunciada y unívoca, los ţerhari. Unos y otros entran por tanto dentro del vasto conjunto Gitanos/Roma según los Gajé.

En general, cada comunidad rom organiza la humanidad a su manera, sin acomodarse a las perspectivas gitanológicas en base a las cuales la totalidad Gitanos/Roma forma una categoría significativa ${ }^{10}$. Existen, como se observa en el caso Gabor, afinidades locales así como la extensión de la cualidad "rom" a otros grupos que no son estrictamente semejantes pero, y esto es lo importante, en ningún momento esta extensión va a coincidir con la clase genérica Gitanos/Roma tal como se ha definido desde hace más de 200 años por las sociedades mayoritarias.

De todos modos, desde una perspectiva circunstancialista según Barth, podemos considerar que los Gabori son de hecho un "grupo étnico": a excepción de algunas tonalidades individuales y familiares, ordenan de manera análoga el vasto campo de los Otros. Se evidencia, en cambio, la dificultad de definir una etnicidad común manipulada por el conjunto de los Rom de Rumania.

\section{MÁS ALLÁ DE LA PERSPECTIVA ÉTNICA: ALGUNAS PISTAS DE REFLEXIÓN}

¿Su único punto en común no sería finalmente el de ser todos categorizados como Gitanos (ţigani) o, desde hace algunos años, Rroms (Rromi)? ¿Pero ello es suficiente para producir un sentimiento de solidaridad y/o pertenencia? En otros contextos, algunos autores se han aventurado a desarrollar esta idea:

"El hecho de ser nombrados colectivamente acaba produciendo una solidaridad real entre las personas así designadas, aunque sólo sea por el hecho de que, por medio de esta nominación común, se convierten colectivamente en objeto de un tratamiento especial" [el caso de los Latinos o los "beurs", etc.], Poutignaty Streiff-Fenart (1995:158).

De manera particular, A. C. Taylor evoca una lógica contigua:

"Estas etnias pacientemente deconstruidas por los antropólogos se han convertido mientras tanto en sujetos, retomando en muchos casos el discurso etnicista o indigenista utilizado en su ambiente por los dominantes [...]. El problema es saber si la etnicidad reivindicada es de una naturaleza verdaderamente distinta a aquella que les es impuesta".

El estudio de las sociedades rom, y en general gitanas, muestra que este proceso no es sistemático: los Gabori siempre han sido percibidos como ţigani, lo cual hasta el día de

10. Cf. Williams (1984) et Piasere (1985) y sus análisis de lo que denominan el "sistema gitano". Hoy en día, un buen número de Rom rumanos que viven en la región de París y teniendo como vecinos a los Viajeros u otros Rom franceses califican indistintamente estos últimos como Jidani, o sea "Judíos" en rumano: es el término fonéticamente más cercano del "Gitan” francés. 
hoy no ha forjado una solidaridad generalizada con otros grupos designados de la misma forma. En su caso, se puede constatar que la omnipresencia de la "cuestión rom" en la escena política rumana y europea en los últimos veinte años ha acentuado su voluntad de desmarcarse de aquellos que la sociedad mayoritaria percibe como sus "hermanos étnicos".

En mi opinión, el mecanismo descrito anteriormente por Poutignat y Taylor puede llegar a ponerse en práctica cuando los designados comparten con aquellos que designan un mismo modo de definición de la identidad colectiva o, si se prefiere, un mismo mecanismo ontológico. Es a partir de entonces que puede establecerse un juego dominante/dominado, en el que los primeros acaban imponiendo su categorización, como en la situación de los Húngaros en Rumania: la conciencia nacional húngara transilvana se ha desarrollado en gran medida desde que la región se ha relacionado con los principados rumanos, subsumiendo las diversidades regionales y locales y, en particular, la identidad sicule (Szekely). En esta situación, la población minoritaria comparte con las mayoritarias una misma lógica de definición de las identidades colectivas, fundada sobre una base primordialista, siguiendo la retórica nacional: cada "pueblo" posee su historia, su cultura, etc.

En el caso de las sociedades gitanas, y aquí tal vez surge un punto en común, parece otra cosa la que está en juego, contribuyendo a mantener en su lugar el discurso mayoritario, sin dar por sentada una posición sobre la definición de la ontología comunitaria: los Rom saben que los Gajé se equivocan en sus cálculos, y esto es bastante normal, ya que son Gajé. No se trata de luchar contra ello sino solamente "construir con", tratando de mitigar los efectos negativos de la categorización a la vez que desviar sus resortes en su favor, en particular creando "lógicas de excepción ${ }^{11 "}$ ".

Un paralelismo puede ser operado con aquello que, siguiendo a E. Viveiros de Castro, P. Descola denomina en el curso de su trabajo sobre las ontologías, el "qui proquo asumido" característico la "ontología animista", la cual se distingue de las otras tres formas ontológicas y, en particular, de la "ontología naturalista "que rige en nuestras sociedades llamadas modernas:

"En la clasificación naturalista, la especie A se distingue de la especie B porque la especie C lo decreta así en razón de facultades singulares de discernimiento racional que su humanidad le confiere; en la identificación animista, yo me siento como miembro de la especie A, no sólo porque yo difiero de los miembros de la especie B por atributos manifiestos, sino debido a que la misma existencia de B me permite saberme diferente

11.¿Debemos constatar aquí el fundamento de este "segundo grado", citado de manera recurrente en la observación de las sociedades gitanas, con motivo de las relaciones de broma/burla/ridiculización mantenidas con los Gajé? A menudo, los Gitanos no se afirman como "crédulos" -ellos saben- mientras que los Gajé se supone que experimentan el mundo en primer grado. Cf. por ejemplo, Stoichiţă (2008). 
puisqu'il nia pas sur moi le même point de vue que le mien. En suma, la perspectiva del supuesto clasificador debe ser aquí absorbida por el clasificado de manera que este pueda verdaderamente considerarse como separado del otro. [...] No hay necesidad de ser beligerante y tener enemigos para poder contemplarse a través de la mirada de otra tribu-especie: los muy pacíficos Chewong de Malasia así lo hacen cuando atribuyen a los animales o los espíritus un punto de vista sobre el mundo y, por tanto, en relación a ellos, diferente al suyo. Según la perspectiva de un Chewong, el tigre y el elefante se equivocan cuando ven lo que no es, pero este error, por el simple hecho de demostrar la capacidad de poseer una visión diferente de la suya, es indispensable para situarlos en su propia clase. En suma, el quiproquo assumées constitutivo de la caracterización de la especie anímica como colectivo, por contraste con la definición de la especie natural donde uno busca a cualquier precio singularizar una clase sin equívocos" (Descola, 2005, 351-353).

Comparación no es igual a razón, y el paralelismo establecido entre los Chewong y los Rom no convierte a los segundos en "primitivos exóticos", ni transforma a los Gajé en tigres y elefantes. Ello no impide que tal perspectiva amerite tal vez ser explorada. Esto permite renovar el enfoque de las ontologías rom, superando las lógicas primordialistas y circunstancialistas (incluyéndolas al mismo tiempo) y, en este contexto, posibilita acercamientos pertinentes y fructíferos en el análisis de las diversas sociedades denominadas gitanas, sin tomarlos nunca por evidentes o dados a priori.

"Los caminos que elige la toma de posesión manouche-toma de posesión de sí mismo, del mundo- induce a pensar que la presencia manoucheno aparenta mermar la soberanía de los Gadjé sino expresar que la omnipotencia de los Gadjé no parece perturbar la integridad de los Mānuš", escribe Williams (1993:60) en su libro sobre los buissonniers del Macizo Central. La fórmula es también pertinente para los Gabori. ¿Y cómo no podía ser de otra manera? ¿Cómo la omnipotencia de los Gajé podría "perturbar la integridad de los Gabori" cuando las diferencias asumidas son las razones de la relación y su misma posibilidad?

Además, el discurso exterior tendente a homogeneizar para un mejor control, al menos cognitivamente ("Vosotros sois Gitanos/Roma, con estas características, con estos problemas, etc."), a pesar de su persistencia y del poder socio-económico de aquellos que lo manipulan, es en gran medida incapaz de desafiar la experiencia íntima y cotidiana: persiste como mecanismo teórico y abstracto ${ }^{12}$ cuando la pertenencia colectica es un hecho cotidiano. Los estereotipos impuestos por el medio social (positivo o negativo) desempeñan un papel en las relaciones sociales, sobre todo en el momento de las interacciones impersonales de la denominada vida moderna (en las instituciones, en el hospital, frente a la policía, etc.), no obstante estas últimas no agotan la experiencia que

12. Salvo, bien entendido, durante los momentos dramáticos de los que la historia contemporánea no está exenta. 
los Rom puedan tener del mundo, afortunadamente.

Se dice a menudo, el término "Rom" significa "hombre". En realidad, hay más: el género, el estatus social y la pertenencia comunitaria son perfectamente indisociables. "Rom", por tanto, se refiere más bien a la idea de "hombre casado entre semejantes ${ }^{13}$ ", estos últimos no conforman un género abstracto e indefinido. La sociedad se compone, en cambio, de un conjunto dado eidentificable de individuos, conectados entre sí. Nadie conoce directamente a todo el mundo y, de hecho, los límites de esta red social son siempre borrosos (todo es cuestión de posición relativa), pero la idea de una trama limitada en la que todos los individuos pueden estar emparentados y, literalmente, identificados, por la sangre y/o la alianza, es suficiente para mantener la tautología identitaria: "Nosotros somos semejantes porque nuestros padres lo eran y nuestros hijos lo serán”.

De manera significativa, cuando un Gabor se informa indirectamente sobre la identidad de alguien afín, no pregunta “QQuién es?”, sino “[Este] ¿Qué es?”"14:"¿[Kodo] Savo’i ?”. Del mismo modo, el uso sistemático de los pronombres definidos delante de los nombres ( $o$ Ianko -el Ianko; $e$ Veta -la Veta) enfatiza la idea de un colectivo limitado de individuos. Desde este punto de vista, en romanés el término "Rom" no es estrictamente hablando un etnónimo: no se refiere a una filiación genérica sino a la experiencia social.

Jean-Pierre Liégeois evocaba en 1976 una Mutationtsigane, Révolutionbohémienne con la cual comenzó a emerger una "nueva conciencia" identitaria, unitaria y política en el seno de diversos grupos gitanos -lo cual, sea dicho de paso, atestigua la ausencia de tal "conciencia" hasta el presente. Hoy en día, más de treinta años después, ¿la "revolución" ha penetrado en profundidad en las comunidades respectivas? Los movimientos militantes, asociaciones y otras federaciones son sin duda más numerosas, más visibles y desempeñan un papel importante a nivel público (la demanda institucional ha aumentado especialmente con la construcción europea y la ampliación hacia la Europa del este), pero como reconoció el propio Liégeois recientemente, "por el momento todavía [...] los innovadores [en el compromiso militante] son considerados por muchos como tránsfugas que abandonaron la sociedad gitana o no estaban suficientemente comprometidos" (Liégeois, 1994:255).

Por otra parte, el creciente número de organizaciones político-asociativas rom rumanas denominadas "representativas" en el curso de los últimos veinte años puede ser interpretado como un reflejo de un "cambio profundo" (Liégeois, op. cit.), pero es

13. No se dice de los niños que son Rom, como se dice de nosotros que somos franceses u otros. Son hijos de los Rom, distintos de los hijos de los Gajé (respectivamente şavo/şej y raklo/rakli) pero no serán Rom y Romni más que una vez casados.

14. El simple “iquién es este?” está reservado a los Gajé y otros Gitanos. 
también la constatación de esta ausencia de sentimiento unitario ${ }^{15}$. La situación no es fundamentalmente diferente respecto a otros países europeos, como lo demuestra el ejemplo austríaco en donde el paisaje asociativo refleja exactamente la diversidad comunitaria: algunos prefieren permanecer invisibles mientras que otros juegan la carta de la representación institucional (Baumgartner, 2010).

$\mathrm{Si}$, a nivel local, otros fenómenos sociales parecen vincular a algunos grupos gitanos, al menos ocasionalmente, como el desarrollo del pentecostalismo en Francia gracias al cual las diversas comunidades participan en las mismas convenciones estacionales, el éxito de este reagrupamiento no parece estar motivado principalmente por una "conciencia identitaria” global (cf. P. Williams, 1987).Por su parte, G. Loiseau interpreta el fenómeno de esta forma:

Al amparo de esta religión los Gitanos logran controlar su imagen de acuerdo a las expectativas de los Gadjé. [...] La identidad religiosa favorece así la identidad étnica global. Al mostrar una imagen construida por los Gadjé (la de un pueblo unido), los Manouches, Gitans y Roms cristianos no ceden nada de sí mismos. Y es probable que continúen viviendo sus divergencias "internas" sin que sea necesario ponerlas de manifiesto ante los Gadjé (Loiseau, 2004:120).

\section{CONCLUSIÓN}

Como mencioné en la introducción, el propósito de este artículo no era aportar una respuesta definitiva a la pregunta “¿Los Rom son una minoría étnica?”, y vimos por qué. Además, mi propuesta no pretendía cuestionar (tampoco suscribir, por otra parte) la pertinencia y/o la legitimidad política de las empresas militantes rom.

Sin lugar a dudas, el antropólogo se encuentra en una posición incómoda cuando su intervención no subscribe aquellas realizadas por otros quienes se expresan en nombre de su "objeto de estudio" (cf. las observaciones de L. Piasere citadas en la introducción). ¿Pero debe por tanto renunciar a hacerse escuchar como lo que es, ni más ni menos, es decir, un observador tratando de dar cuenta de la mejor manera posible de las realidades y, esto es esencial, produciendo un discurso abierto y argumentado con la pretensión de ser debatido? No lo creo.

Por supuesto que la producción académica tiene un papel que desempeñar en la Ciudad:

15. He aquí una muestra no exhaustiva: Partida Romilor, Federatia Conventia Cadru a Rromilor, Federatia Etnica a Rromilor, Partidul Democrat al Rromilor, Lautarilor si Rudarilordin România, Partidul Democrat Crestin al Romilordin România, Aliantapentru Unitatea Rromilor, Asociatia Studentilor Rromi, Centrulpentru Interventii si Studii- Romani Criss, Centrul de Politici Publice Aven Amentza, Astra-Satra, Agentia de Dezvoltare Impreuna, Asociatia Femeilor Rromedin România, Fundatia Phoenix, Comunitatea Etniei Rromilordin România, fundatia Ion Budai Deleanu, Fundatia Social Culturala a Rromilor "Ion Cioaba" etc. Cabe señalar que los movimientos representativos rom concurrentes existían ya en Rumanía en los años 1920-1930. 
no es el de inspirador de políticas "objetivas", que es precisamente lo que yo he denunciado en la introducción al caso de los Gitanos, ya que el conocimiento científico no es legal y no se impone necesariamente como una autoridad, como fundamento unívoco a la acción pública (cf. Weber, 1965) sino una función crítica, cuestionando sin cesar las ideas preconcebidas y otras evidencias, en sus fundamentos cognitivos como en sus consecuencias sociales. No por el placer de la retórica, sino porque este es el resorte propio del pensamiento científico (cf. Bachelard, 1975).

La antropología no detenta un monopolio de la descripción de las cosas "tal como son" y, de hecho, pocas disciplinas de las ciencias sociales han llevado más lejos la autocrítica en el curso de los últimos veinte años ${ }^{16}$. No obstante, la antropología se ubica en una posición original para complacerse, en un contexto político y social en el que la complejidad y los matices parecen cada vez más inútiles, por no decir "peligrosos, siendo el ejemplo de los Rom, convertidos en un "problema público" a resolver, desde este punto de vista elocuente. E inquietante.

16 Ver por ejemplo, para las diversas formas (con frecuencia concurrentes) de la introspección antropológica contemporánea: Clifford y Marcus (1986); Geertz (1996); Fabian (2006); y, para un resumen eficaz de los cuestionamientos presentes, Ghasarian (1997). 


\section{REFERENCIAS BIBLIOGRÁFICAS}

Amselle, J.L. y M’Bokolo, E. (éd.) (1985) Au cour de l'ethnie, Ethnies, tribalisme et état en Afrique. Paris: La Découverte.

Amselle, J.L. (1990) Logiques métisses : anthropologie de l'identité en Afrique et ailleurs. Paris : Payot.

Asséo, H. (2004) «Les Gypsystudies et le droit européen des minorités». Revue d'histoire contemporaine, $\mathrm{n}^{\circ} 51-4$ bis.

Bachelard G. (1975) La formation de l'esprit scientifique. Paris: Librairie philosophique J. Vrin.

Barth, F. (éd.) (1969) Ethnic groups and boundaries. The social organization of culture difference. Oslo: Bergen.

Baumgartner G. (2010) "From Persecution to Recognition: History of the Austrian Roma movement since 1945". Communication au colloque Romani mobilites in Europe, Refugees Studies Center, Universitéd'Oxford.

Bonte, P. et Izard, M. (éd.) (1991) Dictionnaire de l'ethnologie et de l'anthropologie. PUF.

Clifford J. y Marcus G.E. (éd.) (1986) Writing cultures, The Poetics and Politics of Ethnography. University of California Press.

Descola, P. (2005) Par-delà nature et culture. Paris: Gallimard.

Fabian, J. (2006) Le temps et les autres: comment l'anthropologie construit son objet. Anacharsis.

Garo, M. (2009) Les Rroms, une nation en devenir? Éditions Syllepse.

Geertz C. (1996) Iciet là-bas, L’anthropologue comme auteur. Paris: Métaillé.

Ghasarian C. (1996) «Les désarrois de l'ethnographe». L’Homme, nº 143.

Hobsbawm E. y Ranger T.O. (éd.) (1992) The invention of tradition. CUP.

Houliat, B. y Schneck, A. (1999) Tsiganes en Roumanie. Éditions du Rouergue, Rodez.

Huonker, T. y Ludi, R. (2009) Roms, Sintis et Yéniches, La "politique tsigane " suisse à l'époque du national-socialisme. Lausanne: Éditions page deux.

Liégeois J.P. (1994) Roma, tsiganes, voyageurs. Strasbourg: éditions du Conseil de l'Europe.

Liégeois, J.P. (2007) Roms en Europe. Strasbourg: éditions du conseil de l'Europe.

Loiseau G. (2004) "Pentecôtisme, ethnocentrisme et ethnicité tsigane». Religions visitées, Études tsiganes, $\mathrm{n}^{\circ} 20$.

Martinez, N. (1986) Les Tsiganes. PUF, Paris. 
Olivera, M. (2004) “Tsiganes, stéréotypes et idéal type, une approche wébérienne de l'altérité ». Ateliers, Regards ethnologiques, n²8.

Olivera M. (2010) "Introduction aux formes et raisons de la diversité rom roumaine ». Roms de Roumanie, la diversité méconnue. Études tsiganes, vol. 38.

Olivera, M. (2011) Roms en (bidon)villes. Quelle place pour les migrants précaires aujourd'hui ? Paris: éditions Rue d'Ulm.

Olivera, M. (2012) La tradition de l'intégration. Une ethnologie des Roms Gabori dans les années 2000. Paris: éditions Pétra.

Olivera, M. (2012) “The Gypsies as indigenous. The Gabori Roma case in Romania». Romani Studies, vol. 22, n¹5, pp. 1-15

Piasere, L. (1985) Mare Roma, Catégories humaines et structure sociale, Une contribution à l’ethnologie tsigane. Paris: Études et documents balkaniques et méditerranéens, vol. 8.

Piasere, L. (1989) “Les amours des tsiganologues ». En Williams, P. (éd.) Tsiganes : identité, évolution. Paris: Syros.

Piasere, L. (1994) "Les Tsiganes sont-ils «bons à penser» anthropologiquement ? ». Jeux, tours et manèges, une ethnologie des Tsiganes, Études Tsiganes, 2/1994.

Poutignat P. y Streiff-Fenart J. (1995) Théories de l'ethnicité. Paris: PUF.

Stewart, M. (1997) The Time of the Gypsies. Oxford: Westview Press.

Stewart, M. (éd) (2012) The Gypsy "Menace ». Populism and the new anti-Gypsy Politics. Londres: C. Hurst \& Co Publishers.

Stoichiţă, V. (2008) Fabricants d'émotion: musique et malice dans un village tsigane de Roumanie. Nanterre : Société d'ethnologie.

Vitale, T.; Claps E. y Arrigoni, P. (2009) "Regards croisés. Anti-tsiganisme et possibilité de «vivre ensemble», Roms et Gadjé, en Italie ». Sommet européen sur les Roms, Études tsiganes, vol. 35 .

Weber, M. (1959) Le savant et le politique. Paris: Plon.

Weber M. (1965) Essais sur la théorie de la science. Paris: Plon.

Weber M. (1971) Économie et société, tome 2. Paris: Plon.

Williams, P. (1984) Mariage tsigane, Une cérémonie de fiançailles chez les Rom de Paris. Paris: L'Harmattan-Selaf. 
Williams P. (1987) "Le développement du Pentecôtisme chez les Tsiganes en France : mouvement messianique, stéréotypes et affirmation d'identité ». En Vers des sociétés pluriculturelles: études comparatives et situation en France, Actes du colloque international de l'AFA. Paris: Éditions ORSTOM.

Williams, P. (1993) Nous, on nien parle pas, les vivants et les morts chez les Manouches. Paris: éditions de la MSH. 